\title{
Ethical dimension of circle Integrative Community Therapy on qualitative research*
}

\author{
ÉTICA EM PESQUISA E A TERAPIA COMUNITÁRIA INTEGRATIVA
}

ÉTICA Y TERAPIA INTEGRATIVA COMUNIDAD

\author{
Paula Renata Miranda dos Santos ${ }^{1}$, Elisangela Cerencovich², Laura Filomena Santos de Araújo ${ }^{3}$, Roseney \\ Bellato $^{4}$, Sonia Ayako Tao Maruyama ${ }^{5}$
}

\begin{abstract}
This study discusses ethical issues in research involving human beings and seeks to understand the relationship between the ethical care of circle Community Therapy Integrative based on Resolution $466 / 12$ of the National Health Council, the Ministry of Health of Brazil. This is a documentary research, which analyzed the Resolution 466/12 and the circle CTI seeking to make a connection between ethical guidelines contained in both. The analysis of the corpus directed to the construction of the following results: the person's perception, cultural diversity and community. It also brings considerations of the ethical dimension circle of CTI on qualitative research. We conclude that CTI circle is innovative in the sense of the diversity of its participants and respect for cultural and social differences. It is guaranteed, by this way, the wealth of information that it comes to social research as well as, ethical guidelines, including, regulated by Resolution No. 466/12.
\end{abstract}

\section{DESCRIPTORS}

Ethics, Research

Qualitative Research

Ethics Committees, Research

Therapy

Therapeutic Community

\section{RESUMO}

Este estudo discute os aspectos éticos em pesquisa envolvendo seres humanos e busca compreender a relação entre os cuidados éticos da roda de Terapia Comunitária Integrativa baseados na Resolução n-466/12, do Conselho Nacional de Saúde, do Ministério da Saúde do Brasil. Trata-se de uma pesquisa documental, onde foram analisadas a Resolução nำ466/12 e a roda de $\mathrm{TCl}$ buscando fazer uma relação entre os cuidados éticos contidos em ambas. A análise do corpus orientou para a construção dos seguintes resultados: percepção da pessoa, da diversidade cultural e da coletividade. Traz, também, considerações à dimensão ética de Roda de $\mathrm{TCl}$ em pesquisa. Concluímos que roda de $\mathrm{TCl}$ é inovadora no sentido da diversidade de seus participantes e o respeito às diferenças culturais e sociais. Garante-se, por esta forma, a riqueza de informações que dela advém para pesquisas sociais, bem como, os cuidados éticos, dentre eles, os regulamentados pela Resolução n 466/12.

\author{
DESCRITORES \\ Ética em pesquisa \\ Pesquisa qualitativa \\ Comitês de ética em pesquisa \\ Terapia \\ Comunidade terapêutica
}

\begin{abstract}
RESUMEN
Este estudio analiza los aspectos éticos de la investigación con seres humanos y trata de entender la relación entre el cuidado ético de rueda Comunidad Terapia Integrativa basada en la Resolución 466/12 del Consejo Nacional de Salud, el Ministerio de Salud de Brasil. Se trata de una investigación documental, que analizó la Resolución $466 / 12$ y la rueda de CTI que buscan hacer una conexión entre las normas éticas contenidas en ambos. El análisis del corpus dirigido a la construcción de los siguientes resultados: la percepción de la persona, la diversidad cultural y la comunidad. También introduce la consideración de la investigación rueda CTI dimensión ética. Llegamos a la conclusión de que la rueda CTI es innovadora en el sentido de la diversidad de sus participantes y el respeto a las diferencias culturales y sociales. Se garantiza, de esta manera, la cantidad de información que se trata de la investigación social, así como, las normas éticas, incluyendo, regulado por la Resolución N466/12.
\end{abstract}

\author{
DESCRIPTORES \\ Ética en Investigación \\ Investigación Cualitativa \\ Comités de Ética en Investigación \\ Terapia \\ Comunidad Terapéutica
}

\footnotetext{
"Study developed in the discipline "Thematic study: health strategies to work with families", from the Master's Program in Nursing of the Nursing School, Federal University of Mato Grosso (FAEN/UFMT), based on the research carried out by the "Nursing, Health and Citizenship Research Group" (GPESC). ${ }^{1}$ Master's student in Nursing at FAEN/UFMT. Member of the GPESC. ${ }^{2}$ Master in Nursing, FAEN/UFMT. Member of the GPESC. ${ }^{3}$ Ph.D. in Nursing. Professor at FAEN/ UFMT and leader of the GPESC. ${ }^{4}$ Ph.D. in Nursing. Professor at FAEN/UFMT and member of the GPESC. ${ }^{5}$ Ph.D. in Nursing. Professor at FAEN/UFMT and leader of the GPESC.
} 


\section{INTRODUCTION}

Worldwide, ethical standards for research involving human beings aim to consider what "a particular society considers right and just to guide the behavior of researchers in a given historical moment." The guidelines proposed in the Nuremberg Code of 1947 and in the Declaration of Helsinki of 1964, which have been reviewed several times since, aim to regulate biomedical and behavioral research in a particular manner, among other aspects(1 p764).

In Brazil, following the global trend with regard to the Nuremberg Code and the Declaration of Helsinki, research is regulated by the National Health Council of the Ministry of Health. The first Resolution providing for guidelines and regulatory standards for research involving human beings was established in 1996 and the second in 2012. These resolutions are based on the idea that scientific and technological progress must necessarily be guided by ethical engagement and development in order to preserve human ethics while meeting the demands of such progress. Thus, the current Resolution is intended to reaffirm respect for the dignity, freedom and autonomy of human beings ${ }^{(2)}$.

These ethical precepts have been of concern to the Nursing, Health and Citizenship Research Group (GPESC) of the Nursing School of the Federal University of Mato Grosso (FAEN/UFMT), of which the authors of this work are members, throughout the development of research involving human beings in the area of health and nursing. The research group has chosen to utilize the qualitative approach, considering it to be consistent with the effort to understand the experiences of people and their families in life, care and illness situations. Such experiences have raised different subjects of study, including the disease process, rights and health care, as well as the ethical-social and cultural issues intertwined with these subjects.

In the qualitative approach to research, the collection of information is a step of paramount importance, consisting of a social interaction ${ }^{(3)}$ in which "nothing is given": everything is built, and built by someone who is a subject, who has interests and ideology. It is important that researchers make explicit the position from which they speak and contextualizes the situation in which they conduct their studies ${ }^{4(\mathrm{p} 88)}$. Certainly, such collection of information implies that "the other" in the interaction is an active participant in the study. This process is an open experience for both who are, in the encounter, getting to know and recognize each other.

In this sense, we value the interaction established between researcher and research participant, as it is in this and from this relationship that the substantive construction of the corpus of the investigation occurs; therefore, this step is crucial for the research. Naturally, such construction differs from clinical biomedical research, in which the data defined by the researchers are, as a rule, collected by their team from the body of those who agree to participate.
In the development of studies on disease and care experiences, the research group to which we are linked has adopted different strategies to collect information, attempting to establish an interaction that enables the construction of arrangements with each other through the desire for telling and hearing attentively and in an interested way ${ }^{(5)}$. Among these approaches, Integrative Community Therapy (CTI) circles have been shown to be an important mode of approach and interaction in our comprehensive series of studies. We emphasize that substantiation for their use results from Community Therapy(6), developed by Adalberto Barreto. In this study we will use the designation ICT circles, since that is the term currently used by Community Therapists ${ }^{(6)}$.

Intending to employ this resource in teaching, extension and research, researchers of the research group were qualified as Community Therapists. In nursing education, the practice of ICT has been shown to be an important strategy for collective care; in extension, it has been used in healthcare activities within hospital units, clinics and primary care centers; and in research it has been established as a care technology that enables the redemption of the socio-cultural dimension in approaching people and families in disease situations, which is rarely contemplated in professional practice. Thus, ICT has proven to be an important care practice for people in situations involving hospitalization, illness and death and from cancer, kidney failure, ostomy and others, where the course and consequences of the disorder cause intense suffering and, in general, difficulties with transportation to receive health care services. Such situations often challenge socially shared values.

We observed that in such permanent or long-term experiences of disease and care, families are particularly affected in their ways of being and caring; therefore, this is a subject explored in ICT circles. We have also had experiences in using ICT circles with health professionals, who face hard, demanding work in health and are also in need of them.

ICT circles are considered places to share knowledge and life experiences, revealing solutions to overcome daily challenges ${ }^{(7)}$. They are guided by human relationships in service of life values, equality, justice and citizenship ${ }^{(6)}$. Because they involve relationships between people in a quite close way, they must be based on respect and ethics; this supports their "rules".

Implementation of ICT circles as a methodological strategy in our research led us to question how their own rules found support in the determinations regarding ethical care in research. To support such a discussion, we rely on Resolution 466/12, which provides guidelines and standards for research involving human beings in Brazil. This allowed us to demonstrate the ethical considerations that support the ICT.

Thus, this study aims to understand the relation between ethics in research and ICT circles, based on Resolution 466/12 of the National Health Council. 
Given their social recognition as a care practice, in this discussion, ICT circles are proposed as innovative elements in a qualitative approach to research to which we combine the discussion of its ethical foundations, making it a pioneering study based on the experience of the research group.

Aiming to understand the basis of this study, we make explicit the foundations of Resolution 466/12 of the National Health Council as well as of ICT circles, emphasizing how they are established as a research strategy. This mobilized us to deepen reflections on their foundation.

\section{METHODOLOGY}

This is a documentary study that uses existing data ${ }^{(8)}$ and makes use of a qualitative approach that guides the study of interpretations of people with respect to themselves and others ${ }^{(4)}$.

Two documents were analyzed: Resolution 466/12 and the steps used during ICT circles, seeking to make a connection between the ethical guidelines contained in both.

We performed a careful reading of these documents, initiating the steps of the analysis. The first step involved the reading of Resolution 466/12 in order to identify the key ethical aspects in developing and conducting research. The second stage involved the reading of each step of ICT circles according to their developer ${ }^{(6)}$ in order to evidence the ethical considerations that guide them.

In a third stage, both readings allowed us to recognize ethical considerations permeating the steps of ICT circles and their correspondence with the precepts of Resolution 466/12, as well as what is not explicit, highlighting it throughout the text by means of notes. Then, we grouped ideas and expressions about more comprehensive concepts elaborated as categories ${ }^{(4)}$. Thus, the analysis of this corpus guided us to the construction of the following categories: a) perceptions of the individual; b) perceptions of cultural diversity; c) perceptions of collectivity.

\section{RESULTS}

\section{Introduction of the bases of Resolution 466/12 and Integrative Community Therapy circles}

As previously mentioned, the first Brazilian Ethical Resolution was approved by the National Health Council in 1996 and its criteria were based on international laws and guidelines such as: the Nuremberg Code, the Declaration of Human Rights, the Declaration of Helsinki, the International Covenant on Civil and Political Rights, the International Ethical Guidelines for Biomedical Research (CIOMS), the Brazilian Constitution of 1988 and Brazilian legislation $^{(2)}$.
In 2012 the National Health Council approved Resolution 466/12, understanding that over these previous 16 years there had been significant changes in science and technology that needed to be reflected in new guidelines. This resolution, in addition to the already-mentioned laws and guidelines, was based on the Universal Declaration on the Human Genome, the International Declaration on Human Genetic Data and the Universal Declaration on Bioethics and Human Rights. On December 12, 2012, Resolution 466/12 replaced the resolution of $1996^{(2)}$.

The changes in the new Resolution, as a rule, do not affect the way research occurs in the country; however, they approach innovations that involve, for example, genetic mapping, which was not approached in the previous resolution, as well as research involving human reproduction. Another relevant change was the replacement of the term "researched individuals" by "research participants," expanding the understanding of individuals as being actively involved research, and not just as individuals on whom research focuses.

We also highlight that Resolution 466/12 encompasses expansion in relation to the process of acceptance of participants or their legal representatives through the definition of the Free and Informed Consent form. In Resolution 196/96, this appeared only in the definition of what the "free and informed consent" was, but not of the document to be signed by participants or their legal representatives. It defines that the Free and Informed Consent Form must be clearly described to participants, as well as how the stages of the study will be conducted, how the individual will participate in it, how their autonomy, dignity, freedom and privacy will be respected, how the confidentiality of the individual will be guaranteed, what risks and benefits are involved in the research, and what protections will be offered to them ${ }^{(2)}$.

Another interesting element added to the new resolution refers to the "Free and Informed Consent Form", the document intended for the "consent of a participant in the research who is a child, adolescent or legally incompetent," in order to inform participants about all the elements of the research, explaining the "expected benefits, potential risks and inconvenience that may result from the research to the extent of their understanding and respecting their singularities"(2). Therefore, individuals are recognized as rightful persons, and such assent is made accompanied by free and informed consent by the legal representative ${ }^{(2)}$.

However, the most remarkable change in the new resolution, at least in terms of definitions, is possibly pertinent to the more extended understanding of the research process, expanding from the exclusive fieldwork period to the possibility of offering benefits to the population and participants, as well as conclusions and formalized disclosure of results. In this sense, these terms were included: "benefits of the research," "indirect benefits," "findings of
Ethical dimension of circle Integrative Community Therapy on qualitative research

Santos PRM, Cerencovich E, Araújo LFS, Bellato R, Maruyama SAT 
the research" "conclusions of the study," "partial report" and "final report"(2).

Resolution 466/12 also discusses the integration between the National Committee for Research Ethics (CONEP), which represents the Brazilian Ministry of Health, and the National Health Council, represented by Research Ethics Committees. This consists of a system that uses mechanisms, tools and instruments of inter-relation in cooperative work that particularly aims to protect of research participants in Brazil in a coordinated and decentralized manner through an accreditation process ${ }^{(2)}$. This concern with the integration of the system seems have Plataforma Brasil as its most remarkable innovative element, through which submission and follow-up of research is currently made to the Ethics Committee.

However, such a platform also homogenizes all forms of research, giving them a single treatment and making the process visible. Some authors ${ }^{(9)}$ point out that despite the multiplicity of forms of production of contemporary science with an emphasis on Human and Social Sciences research, Resolution 466/12 did not satisfactorily approach the ethical specificities originating from them, although it recognizes those specifities; the resolution also postponed broad ethical consideration of the current production of human knowledge exclusively through the indication of complementary resolution directed to the specificities and particularities of areas. These authors are even considering the regulation of social research by the Ministry of Science, Technology and Innovation (MCTI) instead of the Ministry of Health, among other proposals.

Such proposals are certainly due to inadequacies in the procedures governing resolutions on ethics in Brazil, which generally follow the biomedical research model, so that transposition of this model "[...] to epistemological, methodological and procedural bases of Human Sciences has been shown to be ineffective and, often, an obstacle to conducting research"(9 p212).

Lastly, the new resolution reminds us that there is always a need to incorporate new terms and new guidelines and laws, taking into account that science is dynamic and is always introducing new findings and knowledge; and these must always be based on the ethical precepts required by science itself.

ICT was developed in 1987 in the community of Pirambu, in Fortaleza/CE, as a care technology in programs of mental health support to that population ${ }^{(7)}$. In 2008 the technology was included in the National Policy on Integrative and Complementary Practices of the Unified Health System. This promoted the qualification of health care professionals in order to better cope with social support networks in primary care ${ }^{(10)}$.

The conceptual basis of ICT circles includes systems thinking, the theory of communication, cultural anthropology, the pedagogy of Paulo Freire, and the concept of resilience. They are organized as spaces to promote interpersonal and intercommunity meetings aiming at enhancing the life histories of participants; redemption of identity, self-esteem and self-confidence; expansion of the perception of problems; and possible solutions from local competences $^{(7)}$.

ICT circles are conducted by community therapists and follow the steps of embracement, choice of topic, contextualization, problem-solving or sharing of experiences, reflective conclusion and appreciation. They are also guided by rules of participation, such as not giving advice, not judging, listening to those who are speaking and speaking in the first person ${ }^{(6)}$. This is to respect the individuals who are speaking and to be able to hear each in their own time, motivated by the therapist to express themselves, talking freely about themselves and, on the other hand, exercising attentive listening to others.

The execution of a circle is marked by a preparatory period in which the therapist organizes the execution, place, and space arrangement of the circle and participants; the members are included in this circularity. After this preparation, the circle itself is initiated. After the embracement, we describe the nature and rules of an ICT circle, and at the same time, we try to break the ice between people. Participants are mobilized to interact in the circle by means of the games and singing activities ${ }^{(7)}$.

In our experience of care for individuals and families, ICT circles have improved the following elements at each stage, so that what is described below is part of the experience of the group:

a) Embracement: This is the beginning of the circle, with the embracement of the participants, identification of their expectations, and guidance on the dynamics of the circle. Also, we develop group dynamics aimed at mobilizing interaction between participants.

b) Choice of the topic: This is the time to share suffering; it is associated with personal reports of suffering and life context by each participant. The most recurring afflictions in the reports of participants include: having a disease; having undergone a shocking treatment, concerns about the health of ill persons and their family members; experiencing the impact of illness on work and the financial situation of the family; and having the burden of being the family provider, among others.

c) Contextualization: Subjects that were shared in the circle are listed, and then a single situation is elected, so that the person who exposed it may talk about it, contextualizing it and providing more details: how the affliction is inserted into their life context; their family and social relationships; , their limits in relation to the affliction; and their potentialities. This clarifies the situation for both the person who is experiencing it and the other participants through a shared process that is focused on the person who exposed the issue. 
d) Problem-solving: This is the time to discuss the situation of the individual and share conflicts. Thus, from the situation exposed and elected as the topic in the circle, each individual is invited to share their personal experiences in similar situations, emphasizing ways of coping and overcoming them. At this stage, the person who exposed the situation is asked to remain quiet and listen to the other participants. The usual coping situations are commonly related to afflictions resulting from: shocking diagnoses such as cancer; prejudice; difficulties of family coexistence with ill persons; the burdens of care; and expenses resulting from the care situation, such as financial issues, among others.

e) Reflective conclusion: This is the time when rituals of integration are conducted and positive connotations for the person who exposed the situation are promoted through the personal experiences and history of each participant. In this stage, Participants are also encouraged to look at each other, unite themselves, and talk about the opportunities created by their participation. It is also the time when people have the opportunity to envision and realize the links between them.

At the end of each ICT circle, the therapist leads a discussion about appreciation for how the circle was conducted at each stage, what did not contribute to good performance, and how negative aspects could be changed. This enables the therapist to reflect on the actions, the context in which the circle was conducted, and the relationship with the therapist and among the participants.

\section{DISCUSSION}

\section{Examining Resolution 466/12 and ICT circles}

\section{Perception of the individual}

Resolution 466/12 and ICT circles are concerned with the visibility of the individual. Progress may be observed from the fact that, if in previous Resolution 196/96, individuals were treated as "subjects," in current Resolution 496/12 they are treated as "research participants." In ICT circles, individuals are valued in their life history, relationships, and knowledge built by coping with afflictions, among others.

In this sense, individuals who provide information are no longer subjected to the decisions of researchers; they now become protagonists of their own history. Thus, when thinking beings assign predicates to the world, they identify themselves ${ }^{(11)}$.

This relation of appreciation of human beings gives empowerment to participants in ICT circles, who are instructed to speak in the first-person singular, confirming their presence, participation and occupation.

During ICT circles, participants are referred to their own perception to the extent that there is rule, 'Do not tell secrets'; thus, individuals reflect that despite the singularity and individuality that guides circles, what they tell does not belong to private domain, which demands decisions about what to share. Therefore, the fact is pointed out that there is no way to ensure that what participants share in circles will remain restricted to them.

\section{Perception of cultural diversity}

ICT circles are guided by theoretical axes. One of these axes is cultural anthropology, which understands culture as a reference element for building personal and group identities $^{(12)}$. This understanding guides us to recognize the singularity of each individual and of the cultural diversity that permeates us. This diversity is provided and exposed in ICT circles and may be viewed and recognized as a source of knowledge for the life of each individual.

Thus, recognizing the coexistence of diverse cultures in a same place and respecting them is one of the ethical aspects included in both Resolution 466/12 and ICT circles. These considerations have been moving toward considering different ways of life of people and families, taking into account their habits, culture, and behaviors and the fact that the wealth of each culture lies in the fact that they are different from the others.

Such diversity may be seen when each participant in the circle is given the opportunity to talk, occasioned by the invitation: "Who would like to speak?" Another aspect is the respect that may be observed when the rules are established, as these are intended to organize the dynamics so that each person speaks, clearly and audibly, and listens in their own time and at a given moment in the circle dynamics, implying that the participants may learn about the behaviors, emotion and feelings that are shared in the circle.

Moreover, the existence of rules allows beliefs and behaviors to be respected in an effort to avoid prejudice and value judgments in relation to the shared situations.

\section{Perception of collectivity}

Circles are conducted in a way that ensures horizontal communication without hierarchical levels. Thus, in ICT circles, the collective becomes therapeutic as different people share similar experiences from personal challenges and ways of coping. In the collective interaction the perception of the other is validated through seeing and feeling what the other is expressing, sharing the sorrows, strengthening mutual support, and demonstrating caring and empathy, among other approaches.

ICT circles preserve self-speech at the same time validate the individual as an integrant of a group; therefore, they provide the opportunity for personal manifestation as an experience open to the other. Thus, during circles each person is given the opportunity to conduct themselves in the collective, requiring a certain personal orga- 
nization so that people may talk, be close, listen, and pay attention to emotions, gestures, behaviors and beliefs. This "referral" of each individual in the circle allows this to occur as a communion, setting limits for each at the same time that it offers the possibilities of this group, that is, creating the ambience of circles.

By sharing their experiences in circles, individuals who share their affliction reflect the experienced situation that, as a rule, is recognizable among the participants as a moral issue, as it is full of socially and historically built values. In general, although specific questioned situations have been experienced by particular individuals in a personal way, they carry meanings and values that are also experienced by the others; these are perceived as something close somehow. Thus, the meanings of these afflictions may be achieved and reinterpreted in the sharing in circles. So, as individuals share their experiences and afflictions in circles, values and beliefs become references for each person to relativize their own situation and context, allowing reframing.

\section{Considerations of the ethical dimension under research in ICT circles}

The stages of ICT circles are adjusted to the type of social research ${ }^{(13)}$, as the course of an empirical social study depends at each stage on microdecisions related to particular events that produce different futures, that is, they are unpredictable before their updates, and therefore not subject to strict protocols. These decisions bifurcate into specific plans for ethical considerations.

The establishment of rules in ICT circles denotes a concern with ethics that refers to caring for people, such as the collection of information in research in compliance with Resolution 466/12. Thus, one of the aspects to be observed in ICT circles refers to not doing them with the intent of solving the problems of individuals, but of sharing life experiences ${ }^{(7)}$. In our research group we have valued this knowledge, the knowledge built from personal experience in diverse contexts that integrate life, body, health, disease, family and professional care.

Thus, as a form of group care, ICT circles respect the autonomy and freedom of the participants, as their participation in circles occurs by invitation, as prescribed in the resolution. And, as a modality of research, participation in circles requires the consent of each individual through the Free and Informed Consent form, as determined by ethical care in research. In this form of therapy, therapists are not experts, but they stimulate knowledge from experiences and the bonds of belonging enabled by listening and verbalization.

In the interaction, the suffering of individuals may be shared, and the way each individual defies and faces similar situations is appreciated ${ }^{(7)}$. Certainly, circles are spaces that provide opportunities for individuals to reveal a certain kind of autonomy and freedom.
Thus, it is the role of therapists to make sure that circles have participative dynamics by means of their functional rules, stimulate appreciation of individual choices, and respect the democratic exercise of each person in the groups. They must drive the participants towards resilience and critical consciousness in order to lead them to overcome the position of "I" by their own empowerment, making themselves individuals who are able to contribute so that the others (the group) will listen to their experience. Thus, the rules of ICT circles enable therapists to conduct them while respecting each person in their references so that the principles of ethics are respected.

By valuing popular knowledge, behaviors, everyday experiences and scientific knowledge, ICT aims to respect both forms of knowledge, recognizing that they are complementary ${ }^{(7)}$.

In terms of research, ICT circles are shown to be an interesting modality of interaction with individuals and groups, as well as of collection of information. The content learned from the narratives may give rise to dense material that deserves careful recording and transcription. The transcription is laborious, considering the density of the explained content. Thus, filming circles is recommended, as the image may allow to contribute to a better understanding of the narratives and capture how individuals behave and interact, expanding the meanings of what is being said.

ICT circles consist of the presence of different existences that are able to perceive themselves experiencing suffering that may be shared. The diversity of people is established in the same frame as the circles by the choice of participants, including the therapist who conducts them. Different from each other and yet with particular experiences, people bring to their time in the circles what comes to their minds that they deem important to share with the group at that time. Certainly in ICT circles, each person has a privileged view of the other in the temporal and spatial sense, which allows a field of encounters and approaches of people of different ages gathered in the same historical moment. It is important that they are engaged in the purpose of seeking, in each experience in a disease situation, other definitions and understandings, new parameters of overcoming and coping, review of values, beliefs and demands for care, of themselves and their families, redefining their own lives.

In the research process the appreciation of this diversity of the participants may also be respected, among other ways, in relation the accuracy of the transcriptions of the narratives of the circles, because we seek to preserve their speech, their moments and ways of expression; this aspect is deemed of paramount importance to understanding their experiences. 


\section{CONCLUSION}

ICT circles may be implemented as a strategy to collect information in social research; their own rules and dynamics preserve the determinations of Resolution 466/12 in relation to ethical considerations. Among the precepts of the resolution, it ensures safeguarding participation in the research by means of the Free and Informed Consent form, security of confidentiality, autonomy, and risks and benefits of participation in an activity involving a group, as provided for in the resolution.

ICT circles are innovative, as they enable articulation of the cultural diversity of participants and appreciate the establishment of respect for cultural and social differ-

\section{REFERENCES}

1. Guerriero ICZ, Mianayo MCS. O desafio de revisar aspectos éticos das pesquisas em ciências sociais e humanas: a necessidade de diretrizes específicas. Physis Rev Saúde Coletiva. 2013; 23(3):763-782.

2. Brasil. Resolução n.466, de 12 de dezembro de 2012. Aprova normas regulamentadoras de pesquisas envolvendo seres humanos. Diário Oficial da União, Brasília, jun. 2013. Seção 1, p. 59.

3. Heilborn ML. Antropologia e saúde: considerações éticas e conciliação disciplinar. In: Víctora C, Oliven RG, Maciel ME, Oro AP, organizadores. Antropologia e ética: o debate atual no Brasil. Niterói: UdUFF; 2004. p. 57-63.

4. Minayo MCS. O desafio do conhecimento. Pesquisa qualitativa em saúde. São Paulo: Hucitec; 2010.

5. Araújo LFS, Dolina JV, Petean E, Musquim, CA, Bellato, R, Lucietto, GC. Diário de pesquisa e suas potencialidades na pesquisa qualitativa em saúde. Rev Bras Pesq Saúde. 2013; 15(3):53-61.

6. Camarotti MH, Freire TCGP, Barreto AP. Terapia comunitária integrativa sem fronteiras. Brasília: MISMEC-DF; 2011. ences. This ensures the resulting wealth of information for social research, as well as ethical considerations, including those provided for in Resolution 466/12.

In studies with families, ICT circles proved to be powerful in enabling family members to put themselves as individuals into their references and values, integrating issues in their lives with issues of care in life and disease situations.

Considering that research ethics committees evaluate several aspects of health research, this study proposes a discussion on the ethical aspects that govern social research, taking into account different means of research and groups and families as active participants in health research, at risk of evaluating different issues according to standards that apply only to some of them.

7. Barreto AP. Terapia Comunitária: passo a passo. 4.ed. Revista e Ampliada. Fortaleza: Gráfica LCR; 2008.

8. Gil AC. Métodos e Técnicas de pesquisa social. 6.ed. São Paulo: Atlas; 2010.

9. Carvalho ICM, Machado FV. A regulação da pesquisa e o campo biomédico: considerações sobre um embate epistêmico desde o campo da educação. Práxis Educativa. 2014; 9(1):209-234.

10. Souza GML, Silva PMC, Azevedo EB, Filha, MOF, Silva, VCL, Espinola, LL. A contribuição da terapia comunitária no processo saúde - doença. Cogitare Enferm. 2011; 16(4):682-8.

11. Ayres JRC. Cuidado: trabalho e integração nas práticas de saúde. 1.ed. Rio de Janeiro: CEPESC/UERJ-IMS/ABRASCO; 2011.

12. Geertz C. A interpretação das culturas. 1.ed. Rio de Janeiro: LTC; 2013.

13. Bevilaqua CB. Ética e planos de regulamentação da pesquisa: princípios gerais, procedimentos contextuais. In: Fleischer S, Shuch P, organizadores. Ética e regulamentação na pesquisa antropológica. Brasília: Letras Vivas; 2010. p.71-90. 